\title{
A new technique for difficult biliary cannulation using endobiliary forceps in a patient with a periampullary diverticulum
}

An 83-year-old man attended the emergency room complaining of abdominal pain for 1 month. He had a history of having undergone cholecystectomy and had ongoing chronic kidney disease. His appearance was suggestive of chronic illness and there was tenderness on palpation of the right upper quadrant of his abdomen. On admission, the results of his liver function tests and blood chemistry were as follows: aspartate aminotransferase $31 \mathrm{IU} / \mathrm{L}$, alanine aminotransferase $13 \mathrm{IU} / \mathrm{L}$, total bilirubin $1.0 \mathrm{mg} / \mathrm{dL}$, alkaline phosphatase 59/U/L, y-glutamyl transferase $12 \mathrm{IU} / \mathrm{L}$, white blood cell count $4600 / \mathrm{mm}^{3}$ (reference 3000 $9000 / \mathrm{mm}^{3}$ ), hemoglobin $8.2 \mathrm{~g} / \mathrm{dL}$, creatinine $3.42 \mathrm{mg} / \mathrm{dL}$ (reference $0.6-1.5$ $\mathrm{mg} / \mathrm{dL}$ ), and albumin $2.5 \mathrm{~g} / \mathrm{dL}$. A non-enhanced abdominal computed tomography $(C T)$ scan demonstrated a round calcified lesion of about $15 \mathrm{~mm}$ in size in the distal common bile duct (CBD) (-Fig. 1).

Endoscopic retrograde cholangiopancreatography (ERCP) was performed with a side-viewing endoscope (TGF240; Olympus Optical Corporation, Tokyo, Japan). A huge periampullary diverticulum was visualized; however, the ampulla of Vater was hidden inside the diverticulum (\$Fig.2a). A prominent round lesion, presumed to be the ampulla of Vater, was noted at the 5-o'clock position. We failed to identify the ampullary orifice despite multiple attempts to expose it using suction, torque, or papillotome manipulation [1, 2].

A small-caliber endobiliary biopsy forceps (Olympus, Aomori Olympus Co., Japan) was inserted through the working channel of the endoscope. By grasp-

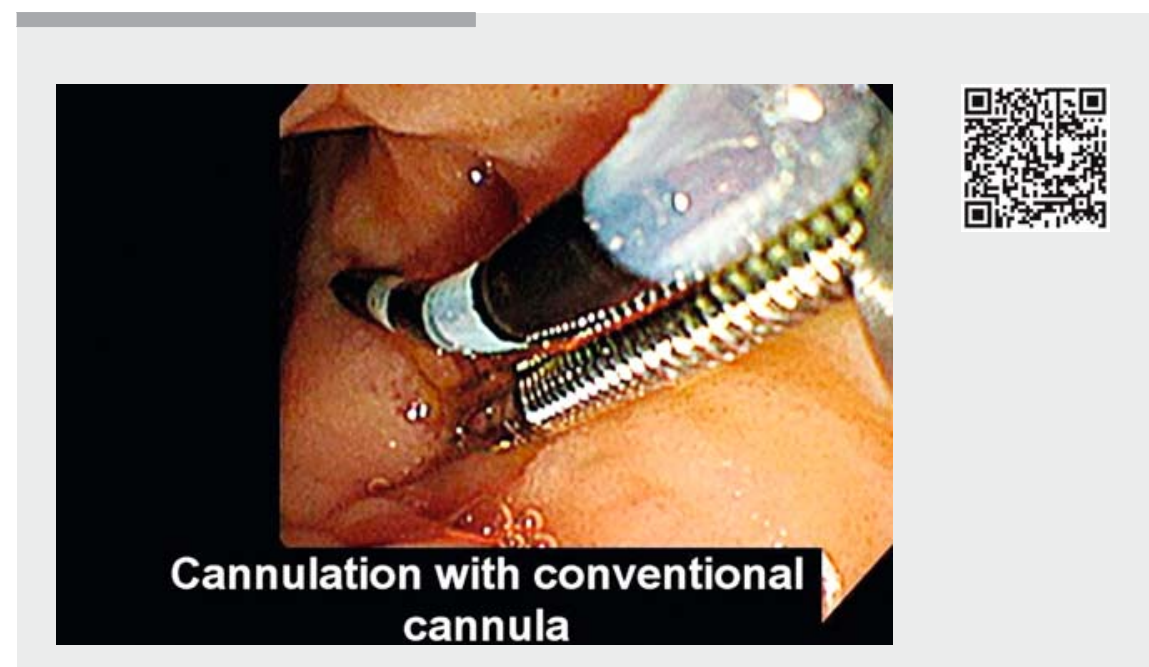

Video 1 A periampullary diverticulum was seen, but the ampullary orifice was not visible. An endobiliary biopsy forceps was inserted through the endoscope to grasp the mucosa and pull it out of the diverticulum, thereby exposing the ampullary orifice. A conventional cannula was advanced through the same channel and the bile duct was successfully cannulated, with a plastic stent then being inserted over the guidewire.

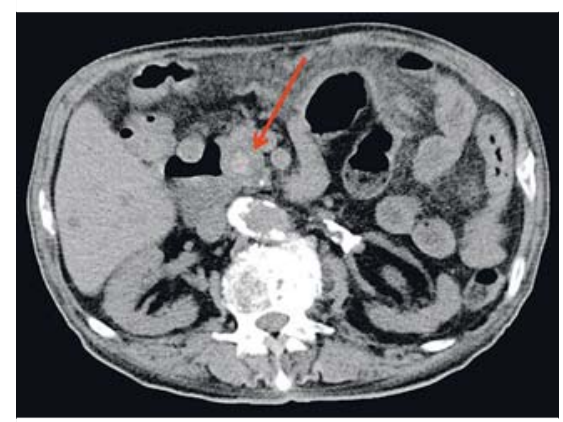

> Fig. 1 A non-enhanced abdominal computed tomography (CT) scan image showing a round calcified lesion of about $15 \mathrm{~mm}$ in size (arrow) in the distal common bile duct.

ing the mucosa with the forceps, we were able to pull the mucosa back out of the diverticulum and the ampullary orifice was eventually turned outward ( $\triangleright$ Fig. $\mathbf{2}$ b; $\triangleright$ Video 1). After the orifice had been identified, the mucosa was secured with the forceps and a conventional cannula (Cook, Winston-Salem, North Carolina, USA) was then inserted through the same working channel, before being smoothly and successfully advanced into the bile duct ( $\boldsymbol{\nabla}$ Fig. $2 \mathbf{c}$ ). Following deep cannulation, a cholangiogram demonstrated a movable filling defect in the distal CBD (> Fig.3). The ductal stone was left intact and a 7-Fr plastic stent was placed into the bile duct over the guidewire ( $\triangleright \mathbf{F i g} .4$ ).

In the present case, we describe a simple but useful technique using a grasp-andpull method as a rescue technique in a patient with an ampullary orifice that was facing inward from the rim of a diverticulum.

Endoscopy_UCTN_Code_TTT_1AR_2AC 

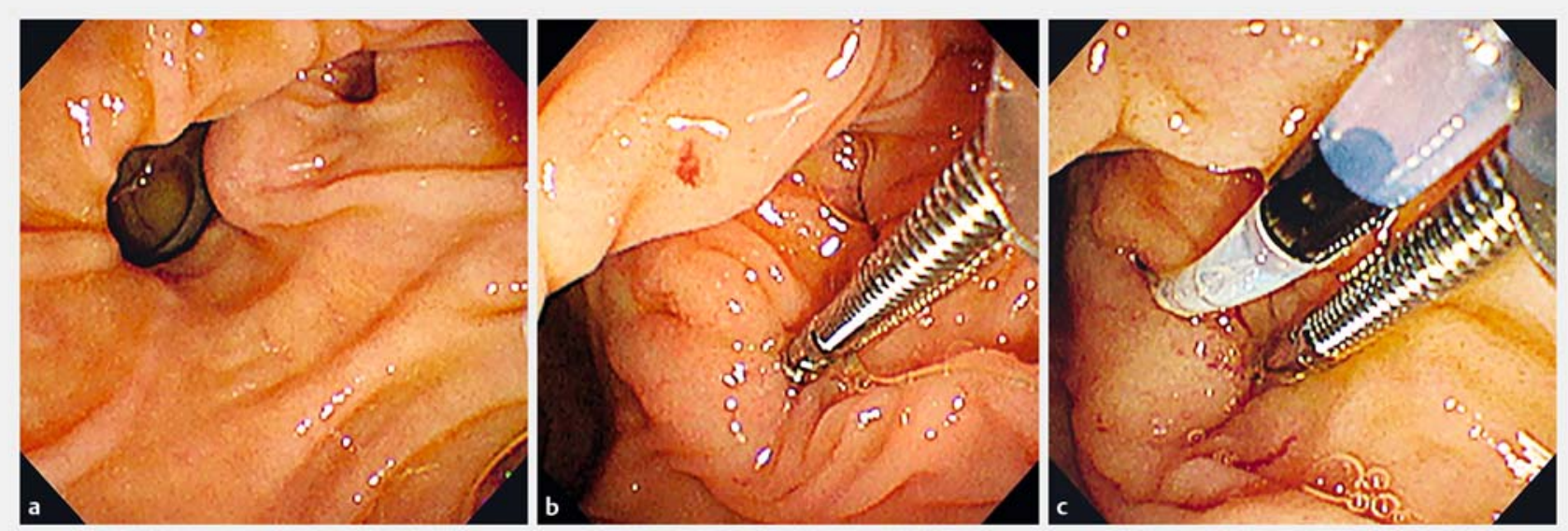

- Fig. 2 Endoscopic images showing: a a huge periampullary diverticulum with a prominent round lesion, thought to be the ampulla of Vater, at the 5-o'clock position, but the ampullary orifice not visible; $\mathbf{b}$ the mucosa being grasped with the endobiliary biopsy forceps and pulled out of the diverticulum to expose the ampullary orifice; $\mathbf{c}$ a conventional cannula smoothly cannulating the bile duct, having been advanced through the same working channel in parallel with the biopsy forceps.

None
The Authors

\section{Kook Hyun Kim, Tae Nyeun Kim}

Division of Gastroenterology and Hepatology, Department of Internal medicine, Yeungnam University College of Medicine, Daegu, Republic of Korea

\section{Corresponding author}

\section{Kook Hyun Kim, MD}

Division of Gastroenterology and Hepatology, Department of Internal Medicine, Yeungnam University College of Medicine, 170 hyunchungro, Nam-gu, Daegu 42415, Republic of Korea Fax: +82-53-6548386

kimkh@yu.ac.kr 


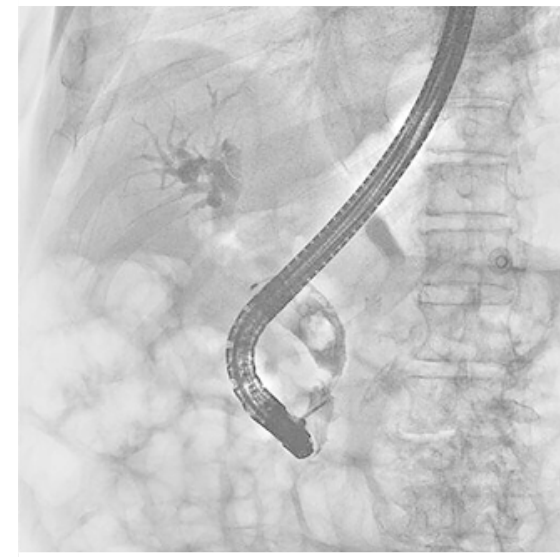

- Fig. 3 A cholangiogram showing a movable filling defect in the distal common bile duct and the biopsy forceps in position.

\section{References}

[1] Elmunzer B], Boetticher NC. Reverse guidewire anchoring of the papilla for difficult cannulation due to a periampullary diverticulum. Gastrointest Endosc 2015; 82: 957

[2] García-Cano J. ERCP cannulation of a hidden papilla within a duodenal diverticulum. Endoscopy 2008; 40: (Suppl. 02): E53

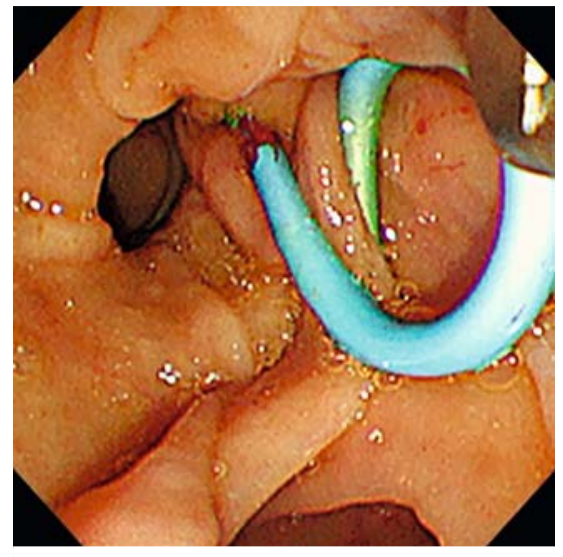

- Fig. 4 Endoscopic imaging showing a 7-Fr plastic stent that was placed into the bile duct over the guidewire.

\section{Bibliography}

DOI https://doi.org/10.1055/s-0043-111010

Published online: 14.6.2017

Endoscopy 2017; 49: 824-826

(c) Georg Thieme Verlag KG

Stuttgart · New York

ISSN 0013-726X

\section{ENDOSCOPY E-VIDEOS}

https:/|eref.thieme.de/e-videos

口血 Endoscopy E-Videos is a free access online section, reporting 田: on interesting cases and new techniques in gastroenterological endoscopy. All papers include a high quality video and all contributions are freely accessible online.

This section has its own submission website at

https://mc.manuscriptcentral.com/e-videos 